\title{
A INFLUÊNCIA DA TECNOLOGIA NA GESTÃO DE UMA AGÊNCIA DE VIAGENS: UMA ANÁLISE A PARTIR DA APRENDIZAGEM BASEADA NA PRÁTICA
}

\author{
Marcelo de Souza Bispo ${ }^{1}$
}

\section{Resumo}

Com o desenvolvimento das novas tecnologias a ideia de organizar assim como de organização vem sofrendo mudanças e impactando o cotidiano empresarial. Nesse sentido, este artigo teve como objetivo analisar a influência da tecnologia na gestão de uma agência de viagens a partir da aprendizagem baseada na prática. A partir de um estudo etnometodológico a pesquisa apresenta como principais resultados uma forma diferenciada de compreender os impactos na gestão de um conjunto de agências de viagens a partir do uso cotidiano da tecnologia nesses espaços.

Palavras-chave: Aprendizagem Organizacional; Tecnologia; Prática; Etnometodologia; Organizações.

\section{THE INFLUENCE OF THE TECHNOLOGY IN MANAGEMENT OF A TRAVEL AGENCY: AN ANALYSIS FROM PRACTICE-BASED LEARNING}

\begin{abstract}
With the development of new technologies as well the idea of organizing and organization is undergoing change and impacting the daily business. Accordingly, this paper aims to analyze the influence of technology in the management of a travel agency from a practice-based learning perspective. From a ethnomethodological study the research presents as major results a different way to understand the impact on the management in travel agencies from the everyday use of technology in those spaces.
\end{abstract}

\footnotetext{
${ }^{1}$ Professor do Departamento de Administração da Universidade Federal da Paraíba. Pesquisador do Núcleo de Estudos em Aprendizagem e Conhecimento - NAC. E-mail: marcelodesouzabispo@gmail.com
} 
Keywords: Learning Organization; Technology; Practice; Etnomethodology; Organizations.

\section{LA INFLUENCIA DE LA TECNOLOGÍA EN LA GESTIÓN DE UNA AGENCIA DE VIAJES: UN ANÁLISIS DESDE EL APRENDIZAJE BASADO EN LA PRÁCTICA}

\section{Resumen}

Con el desarrollo de nuevas tecnologías de la idea de organizar y organización está en proceso de cambio y que afectan la actividad diaria. En este sentido, este artículo tiene como objetivo analizar la influencia de la tecnología en la gestión de una agencia de viajes del aprendizaje basado en la práctica. A partir de un estudio etnometodológica investigación presenta los principales resultados de una manera diferente de entender el impacto en la gestión de un grupo de agentes de viajes disponibles mediante el uso cotidiano de la tecnología en estos espacios.

Palabras clave: Aprendizaje Organizacional; Tecnología; Práctica; Etnometodología; Organizaciones.

\section{Introdução}

Apesar de serem a maioria no contexto brasileiro, as pequenas empresas ainda recebem pouca atenção dos acadêmicos em comparação ao número de pesquisas realizadas em grandes empresas. No contexto das pesquisas em turismo, estudar empresas e organizações não faz parte da agenda dos pesquisadores que atuam especificamente no campo do turismo, cabendo aos pesquisadores em administração, em geral, esta responsabilidade. Nesse sentido, este artigo busca contribuir com o campo do turismo apresentando uma pesquisa realizada em pequena empresa de turismo, agência de viagens, feita com o intuito de contribuir com novos conhecimentos em turismo no que tange a tecnologia e gestão.

A pesquisa foi conduzida em uma agência de viagens com três unidades localizadas na região da grande São Paulo (Brasil) e tinha como foco realizar um olhar mais apurado de como as tecnologias influenciam o cotidiano deste tipo de empresa. Para tanto o marco teórico adotado foi o da aprendizagem baseada na prática (GHERARDI, 2006, 2012; BISPO, 2011; CZARNIAWSKA, 2008; ORLIKOWSKI, 2007) e com a contribuição da etnometodologia (GARFINKEL, 2006; BISPO; GODOY, 2012, 2014; OLIVEIRA; MONTENEGRO, 2012) para a condução metodológica do estudo. 
A partir do exposto, a pergunta norteadora da pesquisa foi: De que maneira a tecnologia influência na gestão de uma agência de viagens? Como desdobramento desta pergunta problema foi eleito como objetivo geral analisar a influência da tecnologia na gestão de uma agência de viagens a partir da aprendizagem baseada na prática.

Além desta breve introdução, o artigo apresenta mais quatro itens que são o referencial teórico que trata de maneira geral da relação entre aprendizagem, organizações e organizações turísticas. Em seguida é descrito o percurso metodológico adotado na pesquisa para na sequência apresentar os resultados e análises. Por fim são tecidas algumas considerações finais do estudo realizado.

\section{Referencial Teórico}

As agências de viagens são organizações que não se limitam a compreensão de que se configuram desta maneira porque possuem uma estrutura formal, hierarquizada e burocrática. Conhecer a dinâmica existente neste tipo de negócio implica aprofundar o conhecimento de como se constrói o seu processo organizativo no cotidiano assim como se combinam as relações dos elementos humanos (sócios, funcionários, clientes, fornecedores, etc.) com os não-humanos (artefatos materiais, culturais, tecnologia, etc.). Esta relação dinâmica dá origem a uma textura organizacional (GHERARDI, 2006, 2012).

Para Czarniawska $(2008,2013)$ e Orlikowski (2007), é preciso também compreender que as organizações não são, necessariamente, constituídas apenas por atores sociais que compartilham um mesmo espaço físico, ou seja, é necessário considerar que nem todas as interações requerem que as pessoas estejam presentes fisicamente, ou ainda, que compartilhem da mesma temporalidade. Assim, as interações mediadas por tecnologia, de forma síncrona ou assíncrona, em um mesmo espaço físico, ou espaços diferentes, devem ser consideradas para o entendimento do que são as organizações na atualidade.

O impacto das tecnologias de informação e comunicação - TIC - nas organizações implica em um redesenho do espaço de trabalho em que o conhecimento está espalhado e fragmentado nas pessoas, nos artefatos, nas regras organizacionais e nos hábitos de modo a serem suportados por uma infraestrutura. Assim, trabalhar a distância requer o desenvolvimento de habilidades para atuação neste espaço fragmentado de conhecimento que estão calcadas em recursos de senso comum (BRUNI; GHERARDI; PAROLIN, 2007; ORLIKOWSKI, 2007).

Reconhecer que as organizações são constituídas por elementos humanos e não humanos leva à compreensão dos locais de trabalho enquanto sistemas fragmentados de conhecimento nos quais pessoas, símbolos e tecnologias atuam juntas para construir e reconstruir o 
entendimento social e a ação organizacional (BRUNI, 2005; BISPO, 2011; BISPO; SANTOS, 2014).

O entendimento do uso das tecnologias enquanto práticas sociais (SUCHMAN ET AL., 1999; ORLIKOWSKI, 2007) contribui para o aprofundamento da compreensão das organizações enquanto contextos sociais uma vez que a tecnologia influencia atualmente a forma dos processos organizativos e a maneira de enxergar e entender as organizações. Posto de outra forma, as tecnologias mudam as maneiras de interação e vivência cotidiana das pessoas, dentro e fora do contexto organizacional, o que nos obriga a considerá-la como parte do agir das organizações.

Nesse sentido, a construção de uma organização, em especial, considerando a influência da tecnologia, remete a um pressuposto de que uma organização é resultado de um processo de aprendizagem coletiva cotidiano, algo que é melhor discutido a seguir.

\section{Aprendizagem e Organizações}

Os processos de aprender e organizar quando compreendidos por uma perspectiva sociológica, especialmente à luz da etnometodologia, estão intimamente ligados em razão do pressuposto que uma organização é construída no seu cotidiano a partir de um processo de aprendizagem coletivo.

A sociologia, segundo Gherardi e Nicolini (2001, p. 47), compreende que a aprendizagem é "algo produzido e reproduzido nas relações sociais dos indivíduos, quando eles participam de uma sociedade". Está integrada no cotidiano das pessoas e é, em grande parte, oriunda das relações sociais informalmente estabelecidas. Assim, é possível dizer que toda atividade, toda prática desenvolvida na vida das pessoas constitui-se numa oportunidade para aprender.

Refletir sobre os processos de aprendizagem nas organizações por uma perspectiva social, pressupõe um olhar interacionista em que a dimensão tácita exerce forte influência no modo de aprender individual e coletivo. Nesse sentido, é possível afirmar que as interações no cotidiano do trabalho é que promovem as condições de aprendizagem a partir de momentos privilegiados de negociação entre os atores que produzem e reproduzem a organização.

O dia a dia das organizações de trabalho é composto pela negociação entre pessoas e grupos na criação do conhecimento, o que envolve o significado das palavras, ações, situações e os artefatos materiais. Todos estes elementos participam e contribuem para o mundo social culturalmente estruturado e constantemente reconstituído pelas atividades de todos aqueles atores que as compõem (GHERARDI, 2006, 2012; BISPO; GODOY, 2012; BISPO, 2013; NICOLINI, 2013). Assim, dentro do contexto sociológico para a compreensão da aprendizagem, os estudos 
no local de trabalho - workplace studies - e os Estudos baseados em Prática - EBP - fornecem suporte epistemológico-teórico-metodológico para pesquisar a aprendizagem coletiva e entender como ocorre o processo de "organizar" dos atores sociais, dando atenção especial para a prática cotidiana dos mesmos.

A constituição da prática aqui neste artigo entendida como o elemento central de análise do processo de organizar (organizing) em que o pressuposto principal é que as organizações se constituem em torno das suas práticas sociais cotidianas, o que Gherardi $(2009,2012)$ chama de práticas de uma organização resultado da textura organizacional formada pela interação dos elementos humanos e não-humanos já definidos neste referencial teórico. Em complemento a este pressuposto, entende-se que a prática individual é situada num amplo campo de práticas as quais se ramificam em todas as direções, do individual para o organizacional e o institucional, assim como qualquer outro sistema complexo.

Ao refinamento cotidiano das práticas e das próprias organizações atribui-se o conceito de taste-making. Gherardi (2009, p. 536) define tastemaking como "um processo discursivo, emergente e coletivo que constantemente refina as práticas e que é feito pelas falas e dito pela ação do 'fazer'". Assim, o taste-making é o processo pelo qual os membros de uma organização buscam aprimorar suas práticas.

\section{Organizações turísticas e aprendizagem}

No contexto das organizações turísticas, a relação entre o processo de organizar com o de aprender e gerar conhecimento é algo também latente, em especial, naquelas de pequeno e médio porte. Contudo, de acordo com Valtonen (2009) este tema vem recebendo pouca atenção do meio acadêmico nas áreas de turismo e administração. A autora destaca que as micro e pequenas empresas de turismo possuem uma gama de possibilidades para serem pesquisadas e estas organizações possuem qualidades epistemológicas que possibilitam pesquisas relevantes, ao contrário do que ocorre predominantemente nas pesquisas na área de administração, em que estas organizações são vistas como "vácuo de conhecimento" ou incapazes na adoção de sistemas eficientes de gestão do conhecimento.

Neste sentido, Valtonen (2009) aponta que as pequenas empresas do segmento turístico contribuem para uma forma distinta da geração do conhecimento, particularmente, quando o foco está em um conhecimento prático. Alguns pontos atribuídos pela autora como relevantes nas características deste tipo de organização são as limitações de caixa, a gestão feita pelos próprios donos, a crença nos mecanismos informais de controle, além do fato de as pessoas realizarem múltiplas tarefas. Assim, estas organizações são descritas como negócios baseados intensamente na interação com os clientes que se configuram em uma relação espaço- 
temporal específica no que tange ao ritmo e às práticas. Em consonância com Czarniawska (2008), Valtonen (2009) ressalta que definir organizações, inclusive as pequenas empresas de turismo, é algo complexo e que também é difícil identificar onde elas "terminam" e os consumidores "começam", em especial, quando se dá atenção às influências tecnológicas.

Estes atributos configuram estas organizações em condições específicas e únicas para um conhecimento baseado na prática. Tais características apontam/levam a crer que os processos de aprendizagem nas pequenas empresas de turismo são pautados nas interações cotidianas das pessoas, lugares e mundo material. Para Valtonen (2009), isto ocorre porque o trabalho em turismo é essencialmente orientado pelas interações que compõem a natureza deste tipo de trabalho. A autora discute que a institucionalização do conhecimento nas pequenas empresas de turismo está pautada em um conjunto de atributos culturais locais, sociais, estéticos, emocionais e simbólicos que estão presentes na aprendizagem e formam conhecimentos específicos que as pessoas utilizam para lidar com as mais variadas situações do seu cotidiano.

Assim, estas organizações precisam ser compreendidas e investigadas com lentes diferentes das usuais utilizadas nas grandes empresas.

\section{Percurso Metodológico}

A pesquisa foi realizada em uma empresa de turismo do segmento de agências de viagem que possui três unidades na região da Grande São Paulo no Brasil. Como forma de garantir o anonimato das pessoas que participaram da pesquisa foram adotados nomes fictícios para elas assim como para a empresa pesquisada que será chamada de VT.

A VT teve o início de suas atividades no ano de 2004, na casa de um dos atuais sócios da empresa. Naquela época os fundadores da empresa foram o Sr. João, um engenheiro, o Sr. José que tinha experiência na área comercial hoteleira, ambos desempregados, e o Sr. Pedro que é primo do Sr. José. Cada um dos sócios investiu duzentos e cinquenta reais (moeda brasileira). Como o Sr. José conhecia várias pessoas do mercado de turismo, no começo ganharam alguns folders de um amigo que tinha uma gráfica, anúncios nas páginas eletrônicas e materiais impressos de empresas parceiras. As emissões de bilhetes de viagem eram realizadas por algumas empresas de amigos do Sr. José que emprestavam o sistema de emissão de passagens para que eles realizassem esta operação. A principal fonte de renda da empresa no início vinha do fato dela ter exclusividade de vendas, em São Paulo, do hotel Tororomba localizado em Ilhéus na Bahia. Foi dessa forma e com estes apoios que a VT ganhou espaço no mercado.

Em 2005, foi inaugurada a primeira loja no bairro da Vila Mariana na cidade de São Paulo (que daqui por diante será mencionada como VM). Os funcionários eram os próprios sócios da VT. Na época da pesquisa a 
VT contava com catorze funcionários, além dos dois sócios. Os produtos e serviços oferecidos pela empresa são atendimento corporativo, viagens e grupos de incentivo, eventos e congressos, passagens aéreas nacionais e internacionais, reservas de hotéis, seguro viagem, locação de veículo nacional e internacional, pacotes nacionais e internacionais, intercâmbios e cursos no exterior, pacotes especiais para lua de mel e formatura, cruzeiros e resorts.

Os participantes da pesquisa foram todos os funcionários da VT, ou seja, dezesseis pessoas, sendo que cinco delas atuam como funcionários em todas as lojas, além dos sócios, dos analistas de marketing e financeiro, e do motoboy. Os demais estavam assim distribuídos: Loja VM - uma gerente, um supervisor, dois atendentes e uma faxineira. É a loja matriz em que os sócios permanecem a maior parte do tempo; Loja PI - dois atendentes; Loja LU - três atendentes e um supervisor.

O método de investigação foi a etnometodologia que busca descrever o ordenamento do cotidiano de um grupo a partir das suas práticas (GARFINKEL, 2006; BISPO; GODOY, 2012, 2014; OLIVEIRA; MONTENEGRO, 2012). Para Rawls (2008) a postura do etnometodólogo implica em não formular perguntas e problemas antes de ingressar no campo de investigação. $\mathrm{O}$ pesquisador deve estar atento aos métodos que os participantes utilizam para fazer algo inteligível, ou seja, não há espaço para concepções a priori. A ideia é utilizar um conceito semelhante ao de suspensão da fenomenologia para que seja possível a compreensão de como são as práticas cotidianas e qual o significado e sentido das mesmas para os membros do grupo em investigação. Garfinkel (2006) denomina este processo como indiferença etnometodológica e esclarece que a principal preocupação do pesquisador, ao estar no campo, deve ser observar e compreender como os membros de um grupo agem a partir de seus pontos de vista, crenças e referências sociais que possuem.

Ten Have (2004) afirma que a pesquisa etnometodológica deve ser dividida em duas fases, a primeira refere-se ao entendimento das atividades em estudo, focando-se na criação de sentido das práticas atribuídas pelos atores sociais que as compartilham, e a segunda, à análise dos métodos utilizados na primeira fase.

A principal técnica de coleta de dados utilizada foi a observação participante com notas de campo. Além dela, também foi feito análise de documentos, conversas informais e uma entrevista semiestruturada. As visitas às lojas da VT tiveram início no dia 29 de Abril de 2010 e se encerraram no dia 05 de Novembro de 2010.

Como a etnometodologia não adota categorizações pré-definidas para análise de dados (TEN HAVE, 2004; BISPO; GODOY, 2012, 2014; OLIVEIRA; MONTENEGRO, 2012), os resultados da pesquisa dessa natureza constituem-se nas maneiras como uma determinada coletividade constrói, perpetua ou modifica uma prática a partir de um conjunto de atividades ordenadas. Portanto, tais resultados são apresentados a partir 
do relato das práticas que foram identificadas dando ênfase nas explicações de como estas práticas são geradas, aprendidas e compartilhadas, assim como elas se modificam, quando é o caso, ao longo do tempo. Com o objetivo de propor uma possibilidade de interpretação dos dados obtidos em campo foi utilizado o modelo proposto por Bispo e Godoy (2014) que se baseia nos cinco conceitos-chave da etnometodologia (realização, indicialidade, reflexividade, relatabilidade e noção de membro) para identificar e nomear um conjunto de atividades como prática. O quadro 1 apresenta de maneira resumida os cinco conceitoschave da etnometodologia.

\begin{tabular}{|c|c|}
\hline Conceito & Conteúdo \\
\hline $\begin{array}{l}\text { Prática / } \\
\text { Realização }\end{array}$ & $\begin{array}{l}\text { Indica a experiência e a realização da prática dos membros } \\
\text { de um grupo em seu contexto cotidiano, ou seja, é preciso } \\
\text { compartilhar desse cotidiano e do contexto para que seja } \\
\text { possível a compreensão das práticas do grupo. }\end{array}$ \\
\hline Indicialidade & $\begin{array}{l}\text { Refere-se a todas as circunstâncias que uma palavra carrega } \\
\text { em uma situação. Tal termo é adotado da linguística e } \\
\text { denota que, ao mesmo tempo, em que uma palavra tem um } \\
\text { significado, de algum modo "genérico", esta mesma palavra } \\
\text { possui significação distinta em situações particulares, assim, } \\
\text { a sua compreensão, em alguns casos, necessita que as } \\
\text { pessoas busquem informações adicionais que vão além do } \\
\text { simples entendimento genérico da palavra. Trata-se da } \\
\text { linguagem em uso. }\end{array}$ \\
\hline Reflexividade & $\begin{array}{l}\text { Está relacionada aos "efeitos" das práticas de um grupo, } \\
\text { trata-se de um processo em que ocorre uma ação e, ao } \\
\text { mesmo tempo, produz uma reação sobre os seus criadores. }\end{array}$ \\
\hline Relatabilidade & $\begin{array}{l}\text { É como o grupo estudado descreve as atividades práticas a } \\
\text { partir das referências de sentido e significado que o próprio } \\
\text { grupo possui, pode ser considerada como uma } \\
\text { "justificativa" do grupo para determinada atividade e } \\
\text { conduta. }\end{array}$ \\
\hline $\begin{array}{l}\text { Noção de } \\
\text { membro }\end{array}$ & $\begin{array}{l}\text { O membro é aquele que compartilha da linguagem de um } \\
\text { grupo, induz a uma condição de "ser" do e no grupo e não } \\
\text { apenas de "estar". }\end{array}$ \\
\hline
\end{tabular}

Fonte: Bispo e Godoy (2014).

No contexto deste artigo, a prática analisada sob os critérios descritos no quadro 1 é a do uso da tecnologia na gestão da VT. Dessa maneira, os dados apresentados e analisados no próximo item são resultado do critério de análise etnometodológico aqui definido.

\section{Análise dos Resultados}


A VT é uma empresa que cresceu rapidamente. Em 2005 ela estava instalada na casa do Sr. José e, em 2009 possuía três lojas, além de um escritório. Tal fato pode levar o leitor a considerar que a empresa possui um modelo de gestão metodicamente organizado e com metas bem definidas. Contudo, a VT cresceu não em razão destes elementos, mas pela vocação empreendedora dos seus sócios e a eficácia na condução dos negócios da empresa, sem necessariamente, recorrer aos modelos ou ferramentas mais conhecidas de gestão empresarial.

O uso da tecnologia na VT é intenso e é parte fundamental no seu processo de vendas, contudo a gestão da empresa não se apresenta da mesma maneira e está longe de incorporar no seu planejamento um sistema integrado de gestão de todas as suas unidades. Nesse sentido, a gestão da VT utiliza a tecnologia essencialmente no apoio à gestão, isto é, a gestão na empresa não segue uma estrutura rígida pautada na tecnologia. Os sócios conduzem este processo com um forte apelo no fazer cotidiano (GHERARDI, 2006, 2012; BISPO; SANTOS, 2014; NICOLINI, 2013) que eles constroem todos os dias, algo que faz da VT uma empresa em constante mudança na sua forma de gerir a organização. Um dos sócios, o Sr. João, logo no começo das visitas na VT comentou o seguinte sobre o processo de gestão.
A gente aprende muito que tem... a gente faz, estuda, vai, faz Pós-Graduação, o cara (o professor) fala de plano de negócios, mas assim...você faz um plano de negócios, mas muito das coisas é instintivo também. É errado? É errado, eu sei que é errado, muitas das coisas que nós fizemos foi instintivamente. Nós também tomamos muito na cabeça por fazer as coisas instintivamente... mas assim, não sabe pra onde recorrer... por exemplo, uma análise de mercado, a gente não sabe se faz uma análise de mercado ou se contrata uma empresa. Às vezes você contrata uma empresa pra fazer uma análise de mercado, pra você sai muito mais caro do que você implantar um negócio. Então você tem que acreditar no seu feeling.

A fala do Sr. João apresenta dois aspectos interessantes e, aparentemente, contraditórios. O primeiro refere-se à valorização dos processos formais de aprendizagem no que tange à gestão de uma organização. Por outro lado, o segundo aspecto expressa a confiança no feeling que parece referir-se a prática da gestão no cotidiano. Uma forma de interpretar esta fala é não enxergar nela, necessariamente, uma contradição, mas uma expressão de uma dificuldade de perceber a condição estática e genérica dos conteúdos aprendidos formalmente na escola - neste caso, Pós-Graduação - na sua dialogicidade com a ação prática cotidiana. Em outras palavras, é ter a consciência da aplicação do 
conhecimento adquirido por meios formais com os processos de aprender e conhecer na prática (GHERARDI, 2006, 2012).

Esta interpretação baseia-se no fato de que a VT possui sim um plano de negócios, inclusive, com uma estratégia bem definida orientada para as vendas, contudo, ele apenas não está posto em uma linguagem que é ensinada na academia. Este plano sofre constantes atualizações em razão da opção, talvez inconsciente, dos sócios em implementá-lo a partir do taste-making (GHERARDI, 2009) que eles desenvolvem no cotidiano e que o Sr. João coloca no termo "instintivamente".

Por outro lado, existe uma necessidade de organizar melhor o processo administrativo da empresa, em razão do seu rápido crescimento. Esta situação é evidenciada na fala a seguir.

Tem uma parte que a gente falha que é uma parte de documentação que a gente não consegue... que a gente não tem muito tempo pra parar e ficar olhando essa parte de documentação na parte de...(registros e arquivos em geral). A empresa ainda está um pouco desorganizada... A empresa ainda está um pouco bagunçada nesse sentido. A gente cresceu, mas não conseguiu acompanhar $o$ crescimento (do ponto de vista de gestão). Porque nós optamos assim, ir pra venda... Claro que tem uma organização, claro, a empresa tem organização... é extremamente saudável, não deve um centavo pra ninguém, ela está organizada. Mas assim, não existe um sistema que suporta tudo isso, agora a gente está implantando um sistema...

O sistema comentado pelo Sr. João é um ERP (enterprise resource system) para agências de viagens. No entanto, ele ficou em funcionamento durante aproximadamente três meses, uma vez que a VT não conseguiu adaptar o seu modo de trabalhar às demandas do sistema. Na entrevista com o outro sócio, o Sr. José, no final do período em campo na VT, fez um comentário sobre esta situação, ressaltando a falta de adaptação ao uso de um sistema tecnológico de gestão.

A gente até tentou implantar um sistema... pra facilitar a gestão dos números tanto pelo financeiro, mas infelizmente não deu certo... é a segunda vez que a gente tenta implantar esse sistema e não dá certo. Muito mais por causa de cultura dos funcionários, de choque de cultura e mudança de hábito... infelizmente isso não deu certo, eu gostaria muito mas... empacou o meu serviço, isso deu uma atrapalhada. Eu tive que abortar. 
A partir deste comentário do Sr. José foi feita uma intervenção para perguntar quais as razões, na opinião dele, que inviabilizaram o uso do sistema de gestão, e ele respondeu que:

Eles (funcionários) lançavam (as vendas)... mas lançavam em tempo errado, lançava informação errada, outros não lançavam. Aí você na época de transição tinha que fazer o trabalho dobrado, aí começou a atrasar o serviço. A gente resolveu abortar, voltar ao sistema mais simples que é o que a gente fazia, mas porém era um serviço que a gente fazia uma vez só.

O sistema mais simples, ao qual o Sr. José se referiu na entrevista, é a gestão das vendas utilizando planilha Excel em que a funcionária do financeiro verifica as vendas do dia anterior junto aos funcionários das lojas. Esta situação do uso da tecnologia na gestão da VT é interessante por suscitar algumas questões: como uma empresa que utiliza fortemente as tecnologias de comunicação e informação para o processo de vendas não faz o mesmo no processo de gestão? Por que o processo de gestão é diferente do processo de organizar (organizing) na apropriação do uso de tecnologias?

Para refletir a respeito dos aspectos envolvidos nestas duas questões, considera-se ser relevante destacar e analisar dois aspectos: a ideia de que organização e gestão fazem parte de um mesmo conceito e, a construção da linguagem para a produção e o uso de tecnologias.

Quando assume-se uma postura epistemológica positivista acerca das organizações (DONALDSON, 1997), parte-se da ideia de que existem limites bem definidos e as ações são orientadas a partir de um modelo de gestão que "molda" o fazer organizacional na sua plenitude, em outras palavras, a gestão seria sinônimo de organizar. Contudo, a organização enquanto contexto social (CZARNIAWSKA, 2008, 2013) nos mostra que a ideia de organizar, neste caso por meio da gestão, não é a organização em si. Portanto, no âmbito da VT, o uso da tecnologia sustenta positivamente o agir organizacional no aspecto que se refere as vendas, uma vez que a tecnologia não aponta, necessariamente, o que a empresa deve fazer, mas ajuda a empresa a fazer. Assim, esta reflexão contribui na compreensão do insucesso na implantação de um modelo de gestão em que o uso da tecnologia, neste caso, orientava como deveria ser o agir da VT. Mais uma vez é possível corroborar com a visão de Suchman et al. (1999) e Orlikowski (2007) quando os autores enfatizam que a tecnologia como prática social só se constitui desta forma quando a sua produção e o seu uso são empregados em contextos situados, algo que está presente nas vendas, mas não na gestão da VT.

É possível então inferir que a gestão na VT desconstrói a ideia de que organização e gestão fazem parte do mesmo conceito. Não pretende-se 
aqui sugerir que a gestão não influi nas organizações, contudo, quer se enfatizar que se tratam de dois aspectos distintos que podem, ou não, se harmonizar dependendo de como a linguagem entre eles é alinhada (Garfinkel, 2006). Esta ponderação possibilita a condição de discutir o uso da tecnologia como prática na gestão da VT e o insucesso na adoção de um sistema com tal função. Neste caso a questão da linguagem parece essencial para ajudar na interpretação da razão pela qual a VT não conseguiu implantar um ERP para contribuir na gestão da empresa. É preciso entender aqui que o problema não estava na capacidade de organizar dos membros da VT, mas na falta de alinhamento entre a linguagem na qual o sistema adotado foi concebido e a linguagem utilizada na VT. Na realidade, como a lógica da linguagem que suporta o sistema não era a mesma que a VT utilizava, tal fato parece ter produzido o insucesso da implantação do mesmo.

Considera-se que o problema não estava na adoção de um sistema de gestão, mas na inflexibilidade do sistema em se aproximar da lógica e da linguagem que já fazem parte da gestão (prática) da VT. Como colocam Suchman et al. (1999) e Orlikowski (2007) um novo artefato (neste caso, o sistema ERP) deve ser desenvolvido no local de trabalho quando o objetivo estiver diretamente relacionado ao seu uso, ou seja, quem faz o sistema deve desenvolvê-lo em conjunto com quem o utiliza. Para os autores, assim como para Bruni (2005), as tecnologias devem ser constituídas inevitavelmente em função de seu uso. Esta interpretação poderia ser contestada por alguns sob o argumento de que o insucesso seria resultado da incapacidade da VT em aprender a utilizar a tecnologia, contudo, não acredita-se nesta possibilidade por duas razões: a VT utiliza muitas tecnologias no seu cotidiano, inclusive, mais complexas do que o sistema de gestão e, como é possível perceber na fala do Sr. José, o problema não estava em manusear o sistema, mas na dificuldade de encaixar o seu uso na dinâmica de trabalho da empresa. Neste aspecto relacionado à dinâmica do trabalho na VT, o comentário do Sr. João representa bem esta situação.

Mais não é fácil não, não é fácil não. É negócio de muitas unidades... e o negócio mais difícil é controlar o ser humano, controlar o profissional..., cada um tem uma limitação, cada um tem um jeito de pensar, isso é muito complicado, isso é muito complicado.

Essa fala, ao considerar a dificuldade de gerenciar um negócio em um ambiente com pluralidade, reforça a ideia de que a gestão em ações apenas topdown, nem sempre, trazem os resultados esperados em razão da organização ser, necessariamente, maior do que a gestão em si. Até porque a gestão é feita por um grupo reduzido de pessoas, na VT duas, que não representam sozinhas o processo de organizar em si. 


\section{Considerações Finais}

Este artigo teve como objetivo analisar a influência da tecnologia na gestão de uma agência de viagens a partir da aprendizagem baseada na prática. Tal objetivo surgiu em razão da necessidade de compreender como uma agência de viagens que possui um grande número de tecnologias para realizar suas vendas e lida com elas de maneira muito eficiente e natural sente tanta dificuldade na implantação de um sistema integrado de gestão. Todavia, mesmo não conseguindo implantar um ERP na empresa, a mesma consegue realizar o processo de gestão, especialmente a financeira, utilizando apenas um software Excel.

Nesse sentido, os resultados da pesquisa apontam que a tecnologia para realização da gestão, no caso da empresa pesquisada, só pode oferecer contribuição efetiva quando construída e apoiada na linguagem e na prática construída pelos membros da organização relativa ao seu fazer cotidiano. Assim, a pesquisa reforça a ideia de que a produção de tecnologia deve sempre estar no local do seu uso ou compartilhar do cotidiano e da prática de onde ela será efetivamente utilizada. Tal situação possibilita que a tecnologia produzida seja um elemento não-humano que constitua, de fato, a textura organizacional na qual ela está ou será inserida e utilizada.

Desse modo, o artigo buscou contribuir na ampliação da compreensão do uso da tecnologia na gestão de pequenas empresas, especialmente as agências de viagens, no que tange o seu processo de gestão, inclusive evidenciando que gestão e organização não são necessariamente sinônimas e que o processo de organizar está em nível de complexidade maior em relação ao processo de gerenciar. Soma-se a isso, a utilização da abordagem da aprendizagem baseada em práticas que possibilita ao pesquisador um aprofundamento da relação "aprender" e "organizar" assim como uma compreensão mais densa do cotidiano organizacional.

Como limitações entende-se que a pesquisa deu maior ênfase a gestão enquanto processo burocrático e operacional na VT e não apresentou resultados e discussões acerca da visão estratégica de gerenciar e o papel da tecnologia nesse enfoque. Assim, surge como possibilidade para pesquisas futuras a análise da influência da tecnologia na gestão estratégica de agências de viagens.

Por fim, cabe reforçar que a construção do cotidiano organizacional por meio das práticas e o seu estudo a partir da aprendizagem baseada na prática se configura como uma abordagem que contribui significativamente para a compreensão do dinamismo que constitui a textura organizacional assim como a complexidade das relações estabelecidas entre todos os atores sociais envolvidos, tanto os elementos humanos quanto os não-humanos. 


\section{Referências}

BISPO, M. de S. Estudos baseados em prática: conceitos, história e perspectivas. Revista Interdisciplinar de Gestão Social - RIGS, v. 2, n. 1, p. 13-34, 2013.

BISPO, M. DE S.; GODOY, A. S. Etnometodologia: uma proposta para pesquisa em estudos organizacionais. Revista de Administração da Unimep, v. 12, n. 2, p. 108-135, 2014.

.; ___. A Etnometodologia enquanto Caminho Teórico-metodológico para a investigação da Aprendizagem nas Organizações. Revista de Administração Contemporânea, v. 16, n. 5, p. 684-704, 2012.

BISPO, M. de S.; SANTOS, I. S. A. A organização do cotidiano na orla de João Pessoa: um olhar etnometodológico da prática do voluntariado. Farol - Revista de Estudos Organizacionais e Sociedade, v. 1, n. 2, p. 379-416, 2014.

BRUNI, A. Shadowing Software and Clinical Records: On the Ethnography of Non-Humans and Heterogeneous Contexts.

Organization, v. 12, n. 3, p.357-378, 2005.

BRUNI, A.; GHERARDI, S.; PAROLIN, L. L. Knowing in a System of Fragmented Knowledge. Mind, Culture, and Activity, v. 14, n. 1-2, p. 83102, 2007.

CZARNIAWSKA, B. Organizations as obstacles to organizing. In: Robichaud, Daniel; Cooren, François (eds.) Organizations and organizing. Materiality, agency, and discourse. New York: Routledge, 2013, p. 3-22.

Organizing: how to study it and how to write about it. Qualitative Research in Organizations and Management: An International Journal, v. 3, n. 1, 4-20, 2008.

DONALDSON, L. A positivist alternative to the structure-action approach. Organization Studies, v. 18, n. 1, 77-92, 1997.

GARFINKEL, H. Studios en Etnometodología. Barcelona: Anthropos, 2006.

GHERARDI, S.; NICOLINI, D. The sociological foundations of organizational learning. In: DIERKES, M.; ANTAL, B. A.; CHILD, J.; NONAKA, I. (orgs). Organizational Learning and Knowledge. Oxford: Oxford University Press, 2001, p. 35-60. 
GHERARDI, S. Organizational knowledge: the texture of workplace learning. Oxford: Blackwell Publishing, 2006.

. Practice? It's a Matter of Taste!. Management Learning, v. 40, v. 5, p. 535-550, 2009.

How to conduct a practice-based study: problems and methods.

Edward: Elgar Publishing, 2012.

NICOLINI, D. Practice Theory, Work, \& Organization: an introduction.

Oxford: Oxford University Press, 2013.

OLIVEIRA, S. A. DE, MONTENEGRO, L. M. Etnometodologia:

Desvelando a Alquimia da Vivência Cotidiana. Cad. EBAPE.BR, v. 10, n. 1, p. 129-145, 2012.

ORLIKOWSKI, W. J. Socialmaterial practices: exploring technology at work. Organization Studies, v. 28, n. 9, p. 1435-1448, 2007.

RAWLS, A. W. Harold Garfinkel, Ethnomethodology and Workplace Studies. Organization Studies, v. 29, n. 5, p. 701-732, 2008.

SUCHMAN, L.; BLOMBERG, J.; ORR, J. E.; TRIGG, R. Reconstructing technologies as social practice. American Behavioural Scientist, v. 43, n. 3 , p. 392-408, 1999.

TEN HAVE, P. Understanding Qualitative Research and Ethnomethodology. London: Sage, 2004.

VALTONEN, A. Small tourism firms as agents of critical knowledge. Tourist Studies, v. 9, n. 2, 127-143, 2009. 